УДК $327: 130.2$

\title{
В.Ю. Даренский
}

\section{«БОЛЬШАЯ ВОСТОЧНАЯ ИДЕЯ» В ПРОГНОСТИКЕ А.С. ПАНАРИНА}

В статье рассмотрены концепты «большой восточной идеи» («идея Великого Востока») и «постэкономизма» в прогностике А.С. Панарина. Показана актуализация этих концептов в современном историческом контексте и необходимость их дальнейшей теоретической разработки. Предложены некоторые теоретические обоснования этих концептов. Западный проект «однополярного» мира предполагает недопустимость воссоздания самостоятельного цивилизационного пространства Евразии, которое чем-либо выделялось бы из общего болота третьего мира. Основная проблема глобального развития, по мнению автора, состоит в том, смогут ли незападные цивилизации воспользоваться своим колоссальным человеческим ресурсом благодаря мобилизации своих культурных традиций.

Ключевые слова: А.С. Панарин, цивилизация, «большая восточная идея», постэкономизм, глобализм, традиция.

DOI: $10.35634 / 2587-9030-2021-5-3-367-373$

Правильная ссылка на статью:

Даренский В.Ю. «Большая восточная идея» в прогностике А.С. Панарина // Вестн. Удм. ун-та. Социология. Политология. Международные отношения. 2021. Т. 5, вып. 3. С. 367-373. https://doi.org/ 10.35634/ 2587-9030-2021-5$3-367-373$

Россия как суверенная цивилизация, способная развиваться независимо от коллективного Запада и противостоять его системной агрессии, уже стала очевидным фактом для всего мира. Важной задачей русской гуманитарной науки является всестороннее обоснование проектов развития российской цивилизации в глобальном контексте. Одним из первых в постсоветский период в этом направлении начал работать Александр Сергеевич Панарин (26.12.1940, Горловка Донецкой обл. 25.09.2003, Москва), выдающийся русский философ, политолог, культуролог, публицист, профессор, доктор философских наук, заведующий кафедрой теоретической политологии философского факультета МГУ им. М.В. Ломоносова (и ее основатель), руководитель Центра социально-философских исследований Института философии Российской академии наук, действительный член пяти академий, в том числе Нью-Йоркской академии наук. Он был автором более 300 научных работ, в том числе 15 монографий и учебников; лауреатом премии имени М.В. Ломоносова за монографию «Реванш истории: российская стратегическая инициатива в XXI веке»; лауреатом Солженицынской премии (2002). Во время учебы на философском факультете МГУ А.С. Панарин входил в группу студентов, в социал-демократическом духе интерпретировавших идеи раннего Маркса и активно обсуждавших политическое преобразование общества. По доносу он был исключен из комсомола и отчислен из университета. Позднее ему удалось восстановиться и закончить заочное отделение факультета, однако к философии и ее преподаванию его не допустили; вплоть до перестройки преподавал социологические проблемы управления, занимаясь философией полуподпольно. Распад страны, утверждение у власти популистско-западнического в своей основе режима и начало экономических реформ по модели «шоковой терапии» круто изменили отношение А.С. Панарина к западническому типу либерализма. Уже в середине 1992 года в своей статье в журнале «Знамя» он сформулировал необходимые «культурологические и геополитические интуиции, обусловленные укорененностью в национальную культуру и традицию» [7. С. 76]. В других многочисленных статьях в периодической печати Панарин выдвигает идею «цивилизованного евразийства».

Целью данной статьи являются анализ и концептуализация одной из поздних идей ученого, ставших своего рода интеллектуальным завещанием А.С. Панарина, требующим дальнейшего творческого развития - «большой восточной идеи» как альтернативного глобального проекта.

В книге «Глобальное политическое прогнозирование» А.С. Панарин прослеживает, как либерализм «утратил мотивы социальной солидарности и сострадательности», в конце концов превратившись в обоснование американского экспансионизма и гегемонизма. Полагая, что современный западный либерализм оказался еще более опасен и разрушителен, чем коммунизм, он проводит параллели между поведением современного Запада и Гитлера, а также сравнивает политику Запада с апартеидом в миро- 
вом масштабе. Соответственно, так называемая политика реформ в России и других постсоветских странах определяется им как социальный апартеид. Как отмечал А.С. Панарин, «как только ситуация диалога двух систем сменилась монологом победившего Запада, с последним стали происходить необъяснимые вещи. Обнажился процесс неожиданной архаизации и варваризации Запада: вместо Запада демократического миру явился Запад агрессивный, Запад вероломный, Запад циничных двойных стандартов и расистского пренебрежения к незападным народам» [6. С. 181]. Западный проект «однополярного» мира предполагает недопустимость воссоздания самостоятельного цивилизационного пространства Евразии, которое чем-либо выделялось бы из общего болота третьего мира. В соответствии с этим проектом «народы Евразии теряют единое большое пространство и погружаются в малые и затхлые пространства, где царят вражда, ревность и провинциальная зашоренность. Они теряют навыки эффективной экономической кооперации, социального и политического сотрудничества, превращаясь в разрозненных маргиналов нового глобального мира. Они теряют язык большой культуры и великую письменную (надэтническую) традицию, возвращаясь к этническим диалектам или даже придумывая их в случае реальной ненаходимости в прошлом» [6. С. 185]. Противодействие описанным процессам, хотя и имеет естественные побудительные мотивы и предпосылки, тем не менее не может начаться и протекать как-то автоматически, но может быть лишь результатом, во-первых, хорошо разработанной стратегии, а во-вторых, волевого усилия активных социальных групп.

В наследии А.С. Панарина до настоящего времени мало обращали внимание на кратко сформулированную им «идею Великого Востока». В книге «Глобальное политическое прогнозирование» он писал: «Евразия может определяться как Великий Восток - этот способ идентификации практически неизбежен ввиду глобального вызова вестернизации, посягающей на исконную биполушарную (западно-восточную) структуру мира. Восточная идея, если ей в самом деле суждено сыграть свою роль в грядущей реконструкции мира, должна стать процедурой открытия качественно новых возможностей для Евразии... Восточная идея необходима Континенту и для того, чтобы предотвратить “конфликт цивилизаций” между конфуцианско-буддистским, индо-буддистским и мусульманским регионами Евразии. Здесь - наиболее значимая точка роста, возбужденная восточной идеей. Континенту необходима настоящая культурная революция, связанная с выработкой межцивилизационных универсалий, интегрирующих его великие цивилизационные миры в единую гибкую, но по-своему целостную (перед лицом внешних вызовов) систему. Предстоит выработать великий симбиоз восточно-христианской, индобуддистской, конфуцианско-буддистской и мусульманской традиций» [2. С. 341-342]. Таким образом, данная идея по-новому реконструирует традиционную культурологическую дихотомию «Запад / Восток». А.С. Панарин выделяет в этой идее три содержательных уровня: 1) культурно-онтологический противостояние вестернизации как процессу секуляризации мира и примитивизации человека; 2) геополитический - предотвращение внутреннего конфликта между не-западными цивилизациями; 3) культуротворческий - симбиоз традиционных цивилизаций как единого пространства, способного противостоять агрессии коллективного Запада.

Однако поскольку восточно-христианская, индуистская, конфуцианско-буддистская и мусульманская традиции внутренне замкнуты и самодостаточны на основе трансляции своих священных текстов, то весьма сложно выработать приниип их реального симбиоза как единого не-западного цивилизационного пространства. Искомая «культурная революция, связанная с выработкой межцивилизационных универсалий», является главной цивилизационной задачей XXI века, которая в настоящее время уже поставлена реально протекающими процессами геополитической консолидации Евразии как ядра не-западного мира. Интеграционные процессы в настоящее время начались в военно-политической и экономической сферах (структуры ШОС и БРИКС), но без большого цивилизационного проекта они не будут иметь под собой достаточно устойчивого основания. Кроме того, как писал А.С. Панарин, «процесс этот представляет не только геополитическую необходимость, ввиду глобального вызова Моря, но и соответствует великим информационным сдвигам постиндустриальной эпохи. Речь идет о постэкономизме, который мы уже не можем понимать в прежнем узкосоциологическом смысле (как активизацию высших вторичных потребностей, связанных с качеством существования). Постэкономизм означает новые приоритеты земной цивилизации в целом, смещение акцентов с инструментальной деятельности, связанной с присвоением богатств природы в угоду “непрерывно растущим потребностям”, на деятельность, связанную с поддержкой экологического, социокультурного и социально-политического равновесия мира» [2. С. 342]. Собственно концепция постэкономизма как мировоззренческого принципа и составляет то основание, которое предлагает А.С. Панарин в качестве общей смысловой и идеологической платформы для всех цивилизаций Евразии. 
Однако постэкономизм является лишь формальным определением, характеризуя принцип развития цивилизации, альтернативный западному проекту человека как «экономического животного» (a в своем предельном варианте - человека как «биосоциального автомата» [1]). Содержательным же смыслом постэкономизма является возрождение сакрального как ядра культуры и мировоззрения. Например, глава 8 книги «Стратегическая нестабильность в XXI веке» имеет характерное название «Возвращение сакрального как альтернатива рыночному терроризму». Вместе с тем понятно, что после процесса секуляризации, который давно уже приобрел глобальный характер, «возвращение сакрального» в том виде, в каком оно определяло массовое сознание в традиционных обществах, становится невозможным. Современные теории постсекуляризма фиксируют тот факт, что сакральные ценности и элементы религиозного мировоззрения сохраняются и возрождаются у современного человека в силу его экзистенциального опыта, а не в силу традиционного религиозного образа жизни, который давно разрушен.

Тем самым люди, которые в настоящее время возвращаются к традиционным религиозным практикам и целостному религиозному мировоззрению, не станут социальным большинством, но составляют фактическую духовную «элиту» общества - по аналогии с варной брахманов в традиционном обществе. Для большинства же населения сакральные ценности и элементы религиозного мировоззрения в настоящее время и в будущем являются своего рода новой «гражданской религией», консолидирующей общество на основе определенной цивилизационной идентичности. Но это фактически становится невозможным в современном западном обществе, где идеологическая обработка населения через СМИ и систему образования носит откровенно антирелигиозный характер, причем даже еще более эффективный, чем в эпоху сталинизма в СССР. Фактически западному обществу в настоящее время целенаправленно навязываются антирелигиозные антиценности (эгоцентризм, гедонизм, содомия и разрушение семьи), которые неизбежно приведут к депопуляции и почти полному вымиранию и ассимиляции этих народов в ближайшие десятилетия, и поэтому эта политика должна рассматриваться как soft-геноцид.

Вместе с тем наш не-западный мир может реализовать альтернативную модель постсекулярной цивилизации. В свое время П. Сорокин определял цивилизационную парадигму будущего следующим образом: «а) нарастающий упадок чувственной культуры, общества и человека и b) появление и постепенный рост первых компонентов нового (идеационального или идеалистического) социокультурного строя» [8. С. 885]. На самом деле картина оказывается более сложной и даже весьма парадоксальной. С одной стороны, ныне «чувственная культура» в материальном (экономическом и военном) отношении стала еще более мощной, подчинив весь мир своим интересам. С другой стороны, она максимально мобилизует внутренние тоталитарные ресурсы в виде усиления идеологической и поведенческой нормативности.

Возвращение к традиционным ценностям и моделям жизни - главный четко прогнозируемый тренд истории XXI века, обусловленный жесткими параметрами выживания в условиях исчерпания энергоносителей и разрушения семьи как института естественного воспроизведения населения. Как внутри коренных народов «золотого миллиарда», так и в старых традиционных обществах, уже обреченных пройти все соблазны Модерна, носителем жизнеспособной модели социальности будет тип человека, способного выжить в условиях краха потребительского общества. Однако в настоящее время страны не-Запада de facto пребывают в стадии интенсивного Модерна и формирования соответствующего ему секулярного типа личности. Это еgо-центричный индивид, целиком сосредоточенный на бытовых интересах и ценностях, сохраняющий некую религиозно-культурную идентичность лишь в качестве реликта, почти не влияющего на его сознание и деятельность. Но в это же самое время в странах, создавших западную цивилизацию, единственно жизнеспособным оказывается уже только тот социокультурный тип личности, который можно назвать неотрадиционалистским. Естественно, восстановление традиционных структур личности и социальности чрезвычайно трудно («ломать - не строить»), оно может происходить лишь локально и постепенно, но иного пути физического самосохранения у народов Запада просто нет.

Это и есть Постмодерн - не в привычном «игровом», но в самом серьезном смысле слова: как исчерпание и самоотрицание Модерна. Однако последний при этом получает свое второе дыхание на огромных пространствах Азии - именно этот регион станет центром мировых процессов в XXI веке. Китай, Россия, Индия, мусульманский мир и регион Юго-Восточной Азии представляют собой самодостаточные в экономическом и культурном отношении миры, каждый из которых даже в отдельно- 
сти потенциально мощнее и жизнеспособнее старых цивилизационных центров - Западной Европы и Северной Америки. Прогноз для последних состоит в утрате ими своей национальной и социокультурной идентичности уже к середине текущего века. Возникает и особая инверсия в культурном сознании людей, относящих себя к европейской традиции. Суть ее в том, что в условиях подлинного Постмодерна культурные ориентации, берущиче начало в так называемом проекте Просвещения» и основанные на императиве эмансипации земного еgо-индивида, оказываются глубокими анахронизмами. Все секулярные идеологии XIX-XX ныне в равной степени оказываются лишь рецидивами агонизирующего Модерна.

Либерализм как современная глобальная идеология наиболее отчетливо несет в себе признаки самоотрицания и саморазрушения Модерна, падения в «новую архаику». А.С. Панарин сформулировал их следующим образом: «Во-первых, либерализм предал ценности прогресса, поставив на место великой временной триады “прошлое - настоящее - будущее" дихотомию “традиционное - современное", попытавшись тем самым увековечить статус-кво, выгодное тем, кто считает себя "единственно современными" на фоне "несовременного" большинства. Во-вторых, он предал ценности европейского рацио, дав карт-бланш сбросившей все “оковы” зоологической чувственности, взявшей реванш над разумом и моралью» [3. С. 236]. На глобальном уровне современный либерализм фактически стал формой глобального трайбализма и расизма, блокируя развитие не-западного человечества путем экономического грабежа через мировую финансовую систему и путем военного диктата: «Прежде европейский колониализм оправдывался то миссией христианства, несущего свой свет погрязшему в грехе мировому язычеству, то миссией просвещения, спасающего “туземцев” от невежества. Отныне глобалистские притязания избранного меньшинства обосновываются откровенно по-расистски: как законные права наиболее приспособленных» [3. С. 254]. Это не традиционный расизм «белой расы» (наоборот, сейчас эта раса максимально дискредитируется в идеологии Запада в качестве носителя традиционных ценностей), но расизм «золотого миллиарда» как мирового эксплуататора.

Для противостояния мировому диктату Запада недостаточно только лишь экономической и военной мощи не-западного мира, которая уже и сейчас превосходит в своей совокупности мощь коллективного Запада, но не менее необходима и идеологическая консолидация не-западного мира как особая цивилизационная альтернатива. В первую очередь это уже вышеупомянутая идеология постэкономизма и стратегия сохранения сакральных традиций как общая «гражданская религия» всх народов и цивилизаций не-западного мира. В свою очередь, это и модель альтернативной глобализации, которая должна противостоять модели «первого» глобализма как глобальной вестернизации (а также прийти на смену «второму», «левацкому» глобализму, реликтом которого на уровне идеологии остается Китай). Как пишет А.С. Панарин, «необходим новый, третий глобализм, предпосылки которого создает планетарная реформация, связанная с качественным преобразованием системы мироустроительных установок и ценностей. И на Западе, и на Востоке о такой реформации говорят уже давно... При этом доминирует идея самоотказа Запада от прометеевой гордыни, от амбиций Просвещения и перехода на позиции, открываемые аскетическо-созерцательной философией Востока... При всем уважении к этим поискам, связанным с благородной самокритикой Запада и легитимацией восточного опыта, я все же не вижу здесь настоящей перспективы» [3. С. 255]. Соответственно, пишет он, реальная «альтернатива гуманистического глобализма может... заключаться в том, чтобы заново синтезировать опыт цивилизаций Востока и Запада, не отказываясь от наследия европейского Просвещения, но корректируя его, исходя из новых глобальных реальностей. Искомая революция сознания требует не отказа от западной просвещенческой рациональности в пользу мистики или от демократических ценностей в пользу авторитаризма» [3. С. 236].

Этот синтез А.С. Панарин определяет как «Новую индоевропейскую идею» и усматривает в ней особую культуротворческую роль России, поскольку «особенность российской судьбы и ее перспективы связаны с возможностью удержать вместе и аккумулировать потенциал всех трех континентальных идей: восточной, южной и индоевропейской. Ибо Россия - это и великий мир восточного православного христианства, издавна противостоящего латинской ереси; и великая печальница и защитница униженного и угнетенного большинства, сегодня олицетворяемого великим Югом; и модернизаторский первопроходец не-Запада, осваивающий достижения западного Просвещения прежде, чем это стали делать Турция, Япония и другие страны» [2. С. 347]. Этот исторический опыт России особенно ценен для идейного синтеза. 
Естественно, что основной мировоззренческой базой искомого синтеза для самой России становится православная традиция - не в узком смысле только церковной традиции, но в более широком, который включает в себя также и русскую классическую культуру, и русский исторический опыт, и особую русскую ментальность, которая сформировалась на протяжении многих веков в условиях симбиоза разных этносов и разных культурных традиций. Хотя эта ментальность во многом разрушена катастрофическими процессами XX века, она реально сохраняется у лучшей части народа и творческих личностей. В книге «Православная цивилизация в глобальном мире» А.С. Панарин отмечал: «Уникальность православной цивилизации в современном глобальном мире состоит в том, что она имеет в своем генезисе первоначально тождественное Западу, но преданное и подавленное им греческое ядро. Это обстоятельство и делает православную цивилизацию носителем имманентной критики западного глобального проекта» [5. С. 516]. Тем самым православная культурная традиция является аутентичной христианской традицией, еще не поврежденной позднейшей секуляризацией и неоязычеством Запада.

В этом качестве православная культурная традиция впервые являет народам Востока христианство в его подлинном виде, а не в виде западных ересей, навязанных европейскими колонизаторами. Эта традиция берет на себя функции сохранения личностного начала в культуре, которое Запад подменил началом индивидуалистическим, разлагающим личность. «Глобальный проект Православия это проект возвращения к новой аскезе... речь идет о свободе в значении творческой аскезы духа, знающего, что участь вещей - не в них самих, не в природных, социальных и иных “детерминантах”, а только в самом духе, ибо лишь ему дана высокая участь открывать иначе возможное там, где все представляется заданным и безальтернативным» [5. С. 569]. На Востоке в Новое время детерминистическое мировоззрение западных колонизаторов, видевших в себе представителей безальтернативного пути развития, быстро соединилось с детерминистическим мировоззрением местных языческих народов, и это дало эффект восточного Модерна с его полным преклонением перед Западом (это имело место и в России). Только православная культурная и ментальная традиция как имманентная критика Запада способна преодолеть этот детерминизм и воспитать волю к самостоятельной исторической жизни. Если в Китае имеет место псевдоморфоза защиты своего исторического бытия в форме абсолютно чуждой ему марксистской идеологии, в Индии, Японии и мусульманском мире - фундаментальное противоречие между вестернизацией и своей локальной культурной традицией, в конечном счете обреченной на уничтожение, то только опыт такой имманентной критики Запада с точки зрения самой христианской традиции, который имеет одна Россия, указывает путь выхода из неизбежного цивилизационного коллапса, на который были бы обречены Евразии. И дело не только в прагматическом принципе «технологии без идеологии», который пытается защитить свою традицию вопреки заимствованию технологий и образа жизни. Нужно сформировать такой тип цивилизации, в котором эти сферы будут ценностно иерархизированы - и не допущена подмена сферы сакральных смыслов сферой прагматики.

Требует радикальной смысловой перекодировки сама традиционная антитеза «Восток - Запад». До сих пор на уровне массового сознания и в России, и отчасти в странах Востока господствует внушенная массовой культурой и вестернизированной системой образования ассоциация Востока с дикостью и «отсталостью», а Запада - со всем самым лучшим, что только может быть. Столь невежественное и инфантильное представление разделяют не только обыватели, но и большинство профессоров российских вузов. Если на Востоке и видят что-то хорошее, то это только максимально вестернизированные Японию и Китай - и именно по этой причине. Такие представления - это сфера культурной мифологии, которая внушается на уровне подсознания и почти никогда не поддается рациональной рефлексии. Это та ситуация, когда требуется контрвнушение. Нужно вернуться к представлению о Востоке, которое существовало и в европейской культуре, но было разрушено в Новое время, когда Восток предстал в первую очередь как объект завоеваний. Это исконное представление о Востоке как истоке всех великих религиозных и культурных традиций, по отношению к которым Запад был лишь учеником. (Дальнее эхо этого исконного представления прозвучало даже во фразе из известного советского фильма: «Восток - дело тонкое».) На самом же деле символическое понимание Востока как истока всего и Азии как «чистоты» («Асии» - от имени народа «асов» - «чистых») заложено в самых основаниях европейского культурного сознания, сейчас основательно забытых (а во многом и сознательно уничтоженных). Возрождение этого базового смысла имен и понятий должно стать важнейшим компонентом евразийской культуры. 
В социальном плане эта иерархизация невозможна без определенного переформатирования представлений о том, что такое общество. Важным компонентом «гражданской религии» не-западного мира должно стать неосословное представление об обществе - не в смысле возвращения старых «сословных привилегий», а в смысле внедрения в массовое сознание людей понимания качественного различия между разными призваниями и видами социального служения. Как отметил А.С. Панарин, «если вспомнить о классической индоевропейской триаде, объединяющей жреца (брахмана), воина (кшатрия) и пахаря, то в будущем нас ожидает, по всей видимости, чрезвычайная активизация двух первых персонажей, как раз и олицетворяющих постиндустриальные функции организаторов и стабилизаторов общества» [2. С. 342]. Но чтобы они смогли выполнить эти функции, в обществе должно воспитываться уважение к этим высшим видам социального служения - воли к сакральному знанию и воли к героическому самопожертвованию - и тем людям, которые специально посвятили себя этому. На уровне массовой психологии это уважение сохраняется в не-западном мире, но оно активно разрушается в настоящее время массовой культурой и системой образования, навязывающими образ так называемого успешного человека, т. е. карьериста и гедониста. Это часть информационной и ментальной агрессии Запада против остального мира, которую в целом можно определить как инфернализацию сознания - т. е. внушение людям такого мировоззрения, которое основано на стремлении к греху, а не к праведной жизни. Поскольку представление о грехе и праведности во всех традиционных религиях Евразии в основном совпадает, то агентов такой пропаганды можно называть инферналами в качестве общего маркера людей западной «антисистемы» в рамках не-западных обществ, в том числе и в России. Такое общее наименование было бы более удачным по сравнению с традиционными терминами «русофобы», «либералы» и т. п., поскольку последние имеют смысл только в специфическом российском контексте и совершенно непонятны для других народов Евразии.

Проект глобальной диктатуры не встречает сопротивления до тех пор, пока у населения деградирующих «затхлых пространств», одурманенных индустрией «промывки мозгов», сохраняется иллюзия возможности вхождения в число стран «золотого миллиарда». Однако когда иллюзорность этих мечтаний станет в конце концов очевидной большинству населения, его политические и цивилизационные предпочтения радикально изменятся. Возможно, на это уйдут даже десятки лет, однако итог предопределен и неизбежен, а сам процесс уже начался. Более того, в определенном смысле можно сказать, что временное разобщение Русского мира, уже далеко не первое в его истории, как и раньше, пойдет лишь на укрепление его дальнейшего единства - после того, как очередная «европейская» утопия продемонстрирует свою полную несостоятельность. У России два пути, констатирует Александр Панарин в книге «Православная цивилизация в глобальном мире»: либо быть самобытной, либо перестать существовать вообще. Наконец, А.С. Панарин вкладывает иной смысл в понятие «сильная государственность». Если ранее в задачи государства входили обеспечение равных условий на рынке и защита производителей и граждан от опасностей произвола чиновников, мафии и сепаратизма, то теперь государство воспринимается как патриархальный гарант всех прав и свобод граждан. Патриархальность государства заключается в том, что все остальные классы и сословия - бюрократия, крестьянство, рабочие и предприниматели - находятся у него на службе. Обосновывая свое новое понимание государственности на историческом материале, Панарин переосмысливает и роль Сталина, оправдывая теперь деятельность «державника-отца». Главной идеей русской политический и социальной философии, по А.С. Панарину, становится идея служения государству («служилая аскеза»).

Одну из последних книг А.С. Панарина «Православная цивилизация в глобальном мире» можно назвать духовным завещанием ученого. Самые острые вопросы современного мира он рассматривал сквозь призму православного миросозерцания, основанного на нравственном противостоянии греху, сострадательности и защите слабых. «Не-западным народам, - писал ученый, - пора взглянуть на себя не сторонними глазами западников, а посмотреть на свое будущее с высоты собственного великого прошлого. Не мимесис, а анамнезис. Не подражание и заимствование, а процедура имманентного обновления на основе “припоминания" своей великой традиции - вот перспективный путь» [5. С. 418]. А в своей известной скандальной статье «Народ без элиты: между отчаянием и надеждой», послужившей поводом для уничтожения тиража книги, в которую она вошла, А.С. Панарин сформулировал фактически свое идейное завещание. Здесь он писал: «Тех, кто не порвал своих связей с великими традициями, переубедить нельзя. Они знают, что по самой своей сути человек не экономическое, а религиозное животное и только поэтому ему дано подняться над животным уровнем. Россия, ставшая эпицентром разрушительной работы глобалистов, не может выжить, не открыв этих новых перспектив. Новый интернационал четвертого мира, который она, по всей вероятности, воз- 
главит завтра, будет воплощением альтернативного глобализма демократических низов. В качестве второго мира, меряющегося с первым по критериям силы и успеха, Россия потерпела поражение и погибла. Возродиться она способна только как четвертый мир, отвергающий ложные критерии и прерогативы первого. Дать этому миру истинное вдохновение - задача постэкономической элиты, обращающейся к народам через голову глобального либерального истеблишмента» [4. С. 75].

Но насколько это возможно? Этот четвертый мир не является утопической фантазией, но реально существует; более того, он фактически охватывает более половины всего человечества - большинство населения не-западного мира. Вопрос состоит только в том, смогут ли не-западные цивилизации воспользоваться этим колоссальным человеческим ресурсом благодаря мобилизации своих культурных традиций. Этим фактором будет определяться история XXI века.

\section{СПИСОК ЛИТЕРАТУРЫ}

1. Даренский В.Ю. Новейший техногенный образ человека: «биоавтомат» // CREDO NEW. 2019. № 4 (100). C. $111-119$.

2. Панарин А.С. Глобальное политическое прогнозирование. М.: Алгоритм, 2002. 352 с.

3. Панарин А.С. Искушение глобализмом. М.: Эксмо, 2002. 413 с.

4. Панарин А.С. Народ без элиты: между отчаянием и надеждой // Наш современник. 2001. № 11. С. 67-75.

5. Панарин А.С. Православная цивилизация / сост., предисл. В.Н. Расторгуев. М.: Институт русской цивилизации, 2014. $1248 \mathrm{c}$.

6. Панарин А.С. Россия в социокультурном пространстве Евразии // Москва. 2004. № 4. С. 181-188.

7. Панарин А.С. Цивилизационный процесс в России: опыт поражения и уроки на завтра // Знамя. 1992. № 7. C. $68-77$.

8. Сорокин П. Социальная и культурная динамика. М.: Астрель, 2006. 1126 с.

Поступила в редакцию 06.08.2021

Даренский Виталий Юрьевич, доктор философских наук, профессор кафедры философии

Луганский государственный университет

91011, Украина (ЛНР), г. Луганск, ул. Оборонная, 2

E-mail: darenski1972@,rambler.ru

\section{V.Yu. Darenskiy \\ THE “GREAT EASTERN IDEA" IN THE PROGNOSTICS OF A.S. PANARIN}

DOI: $10.35634 / 2587-9030-2021-5-3-367-373$

The article deals with the concepts of the "Great Eastern Idea" ("the idea of the Great East") and "posteconomism" in the prognostics of A.S. Panarin. The article shows the actualization of these concepts in the modern historical context and the need for their further theoretical development. Some theoretical justifications of these concepts are proposed. The Western project of a "unipolar" world presupposes the inadmissibility of recreating an independent civilizational space of Eurasia, which would somehow stand out from the common swamp of the "third world". The main problem of global development, according to the author, is whether non-Western civilizations will be able to use their enormous human resources through the mobilization of their cultural traditions.

Keywords: A.S. Panarin, civilization, “Great Eastern idea”, posteconomism, globalism, tradition.

\section{For citation:}

Darenskiy V.Yu. The "Great Eastern idea" in the prognostic of A.S. Panarin // Bulletin of Udmurt University. Sociology. Political Science. International Relations. 2021. Vol. 5, iss. 3. P. 367-373. https://doi.org/10.35634/2587-90302021-5-3-367-373 (In Russ.).

Darenskiy V.Yu., Doctor of Philosophy, Professor at Department of philosophy

Lugansk Pedagogical University

Oboronnaja st., 2, Lugansk, Ukraine (LPR), 91011

E-mail: darenski1972@,rambler.ru 